\title{
Memory Impairment in Aged Primates Is Associated with Focal Death of Cortical Neurons and Atrophy of Subcortical Neurons
}

\author{
David E. Smith, ${ }^{1}$ Peter R. Rapp, ${ }^{2}$ Heather M. McKay, ${ }^{3}$ Jeffrey A. Roberts, ${ }^{3}$ and Mark H. Tuszynski ${ }^{1,4}$ \\ ${ }^{1}$ Department of Neurosciences, University of California, San Diego, La Jolla, California 92093-0626, ${ }^{2}$ Kastor Neurobiology of Aging Laboratories, Fishberg \\ Research Center for Neurobiology, New York, New York 10029, ${ }^{3}$ California National Primate Center, Davis, California 95616, and ${ }^{4}$ Veterans Administration \\ Medical Center, San Diego, California 92161
}

\begin{abstract}
Mechanisms of cognitive decline with aging remain primarily unknown. We determined whether localized cell loss occurred in brain regions associated with age-related cognitive decline in primates. On a task requiring the prefrontal cortex, aged monkeys were impaired in maintaining representations in working memory. Stereological quantification in area $8 \mathrm{~A}$, a prefrontal region associated with working memory, demonstrated a significant $32 \pm 11 \%$ reduction in the number of Nissl-stained neurons compared with young monkeys. Furthermore, the number of immunolabeled cholinergic neurons projecting to this region of cortex from the nucleus basalis was also reduced by $50 \pm 6 \%$. In contrast, neuronal number was strikingly preserved in an adjoining prefrontal cortical region also associated with working memory, area 46, and in the component of the nucleus basalis projecting to this region. These findings demonstrate extensive but highly localized loss of neocortical neurons in aged, cognitively impaired monkeys that likely contributes to cognitive decline. Cell degeneration, when present, extends transneuronally.
\end{abstract}

Key words: aging; cell death; working memory; dorsolateral prefrontal cortex; stereology; cortex; cholinergic

\section{Introduction}

Normal aging is often accompanied by functional deficits in executive processes and declarative memory (Grady and Craik, 2000). The neural basis for age-related loss of cognitive and memory capacity, however, remains unclear. Analysis of working memory, the ability to retrieve and temporarily maintain a memory representation in support of cognitive functions such as learning, reasoning, and planning (Baddeley, 1998; Squire and Kandel, 2000), offers an opportunity to investigate possible causes for decrements in cognition associated with normal aging. Working memory commonly declines with age in both humans (Light and Anderson, 1985; Morris et al., 1988) and nonhuman primates (Walker et al., 1988; Rapp and Gallagher 1997), is subserved by a well defined neural substrate (Ungerleider et al., 1998), and is considered an integral component of the global cognitive decline that occurs in aging (Salthouse, 1992; Briggs et al., 1999). Thus, examining the basis for loss of working memory capacity may provide insights into general mechanisms that underlie age-related deficits in cognition and memory.

Among the potential causes for deficits in working memory are loss or dysfunction of neurons in either cortex or subcortical

Received Sept. 20, 2003; revised Feb. 23, 2004; accepted Feb. 27, 2004

This study was supported by National Institutes of Health, the Alzheimer's Association, the Institute for the Study of Aging, and the Veterans Administration. We thank Dr. Karen Dobkins for helpful comments.

Correspondence should be addressed to Dr. Mark H. Tuszynski, Department of Neurosciences 0626, University of California, San Diego, 9500 Gilman Drive, La Jolla, CA 92093. E-mail: mtuszynski@ucsd.edu.

D0I:10.1523/JNEUROSCI.4289-03.2004

Copyright $\odot 2004$ Society for Neuroscience $\quad$ 0270-6474/04/244373-09\$15.00/0 nuclei that project to cortex and that modulate cortical activity. Whereas most studies reveal no significant loss in the total number of neurons in the aged human cortex (Pakkenberg and Gunderson, 1997; Peters, 2002), few studies have examined agerelated changes in neuronal number in very focal regions of cortex (West, 1993; Simic et al., 1997). A single study that we are aware of investigated the effects of age on neurons of the dorsolateral prefrontal cortex and reported no loss (Peters et al., 1996); however, unbiased stereological methods were not used. Furthermore, no previous study has investigated age-related alterations in neuronal number using stereological methods in discrete neocortical regions in behaviorally characterized primates.

Thus, we behaviorally characterized young and aged rhesus monkeys on a task dependent on the functional integrity of the dorsolateral prefrontal cortex and then performed a detailed stereological analysis of neural circuitry in focal, functionally distinct components of this brain region. We find that cognitive decline with aging is associated with neuronal and transneuronal degeneration in highly selective brain regions, whereas distinct sparing of neural circuitry is present in adjoining cortical regions, indicating a highly selective regional vulnerability of the brain to age-related neural degeneration.

\section{Materials and Methods \\ Behavioral methods}

Rhesus monkeys (Macaca mullata) were subjects of this study. One group consisted of young adult monkeys of mean \pm SEM age of $11.0 \pm$ 0.9 years ( $n=7$; four males and three females), and the other consisted of aged monkeys of mean age of $25.4 \pm 1.2$ years $(n=6$; two males and four 
females). Monkeys were housed at the California Regional Primate Research Center, and animal care conformed to National Institutes of Health and institutional guidelines regarding health, safety, and comfort of experimental animals. A subset of these subjects (four young adult monkeys, mean age of $11.4 \pm 1.5$ years, three males and one female; three aged monkeys, mean age of $24.3 \pm 2.0$ years, one male and two females) was behaviorally characterized. Working memory was tested using a twowell delayed response (DR) task in a Wisconsin General Testing Apparatus at delays of $0,1,5,10,15,30,60$, and $120 \mathrm{sec}$, as described previously (Eberling et al., 1997). Subjects were trained to a criterion of $90 \%$ correct without a delay and then were trained to $90 \%$ correct at a delay of $1 \mathrm{sec}$. Monkeys observed the baiting of one of two lateral wells with a food reward. During the training phase, both wells were covered in view of the subjects, and a clear Plexiglas screen was raised to permit a response. If the correct location was chosen, the subject was allowed to retrieve the reward. Delays were imposed by lowering an opaque screen after the baited and unbaited food wells were covered. Daily test sessions consisted of 30 trials with a $20 \mathrm{sec}$ intertrial interval, with the left and right wells baited equally in pseudorandom order. After reaching performance criterion, testing proceeded using the same daily schedule as in the training phase. Choice accuracy was the percentage of correct responses across 90 total trials conducted at each delay. After completion of behavioral testing, subjects were deeply sedated with ketamine $(10 \mathrm{mg} / \mathrm{kg}, \mathrm{i} . \mathrm{m}$. $)$ and deeply anesthetized with Nembutal (30 mg/kg, i.p.) and then transcardially perfused as described below for harvesting of brains. A detailed history of the behaviorally characterized monkeys is provided in Appendix.

\section{Anatomical methods}

Tissue preparation and histochemistry. Neuronal number and cortical volume were examined using unbiased stereological methods in thioninstained coronal sections of prefrontal cortex. Subjects were transcardially perfused for $1 \mathrm{hr}$ with $4 \%$ paraformaldehyde in $0.1 \mathrm{~m}$ phosphate buffer, $\mathrm{pH} 7.4$, at $4^{\circ} \mathrm{C}$, followed by infusion of $5 \%$ sucrose solution. Brains were stereotaxically blocked in the coronal plane and sectioned on a freezing microtome set at $40 \mu \mathrm{m}$. Sections were collected in cryoprotectant solution in six series, with each series consisting of every sixth section through the rostrocaudal extent of prefrontal cortex. These were maintained at $-80^{\circ} \mathrm{C}$ until processed. A series of one-in-six sections was thioninstained for quantification of cortical volume and neuron number.

Frontal cortex anatomical boundaries. Area 46, found within and on the banks of the principal sulcus, extends from a rostral boundary of the anterior extremity of the principal sulcus to a caudal boundary formed by the anterior extent of the superior limb of the arcuate sulcus, as judged on serial coronal sections (see Fig. 2). For area 8A, the rostral limit consists of the posterior extent of the principal sulcus, and the caudal boundary is formed by the posterior extent of the arcuate sulcus formed at the junction of its superior and inferior limbs, as judged on serial coronal sections (O'Donnell et al., 1999; Owen et al., 1999). This sulcal method of anatomical boundary determination was confirmed using clearly described architectonic characteristics of these cortical regions, as described by O’Donnell et al. (1999). Briefly, compared with surrounding cortical regions, area 46 contains the following: a thicker and denser layer II; darkly stained, medium-sized pyramidal neurons in deep layer III and superficial layer V; and a thin layer IV. Compared with surrounding cortical regions, area $8 \mathrm{~A}$ contains the following: intensely stained and dense pyramidal neurons in layer III; no layer IV; and very large pyramidal neurons in layer V. Cortical layers I-IV were grouped together for quantification and analysis, as were layers V-VI. Corticocortical (Owen et al., 1999; Barbas, 2000) and thalamocortical (Krettek and Price, 1977; Giguere and Goldman-Rakic, 1988) afferents arrive in layers I-IV, which also perform operations native to a specific cortical area (Barbas, 2000; Ongur and Price, 2000). In contrast, deep layers V-VI provide efferent connectivity to other regions of the brain (Pandya et al., 1971; Pandya and Yeterian, 1990). Thus, layers I-IV share common patterns of neural connectivity and functions, as do layers V-VI.

Stereology. Stereology was conducted using Stereo Investigator software (MicroBrightField, Colchester, VT). Live video images were received from an Olympus Optical (Tokyo, Japan) OLY-200 video camera mounted on an Olympus Optical BX60 microscope fitted with a Ludl
99S000 XYZ motorized stage. Neuronal number and morphology and cortical volume were quantified in thionin-stained coronal sections of prefrontal cortex. Cell size was quantified using the nucleator method (Gundersen, 1988), and neuronal number was quantified using the optical fractionator method (West et al., 1996; Long et al., 1999) using the nucleolus as a reference object. This method also reports the volume within which neurons were contained (i.e., cortical volume). The optical fractionator relies on a three-dimensional probe (the optical disector) and a systematic uniform sampling scheme (the fractionator, set at $5 \%$ sampling area) to generate estimates of total cell number unbiased by tissue processing artifacts or assumptions regarding neuronal size and shape. For each frontal region quantified, the $5 \%$ sampling fraction was based on preliminary estimates of neuronal number; sampling was optimized to produce a coefficient of error lower than the biological variability. Within each optical dissector, cells were counted only if the nucleolus reached focus within the disector sampling frame, which was set at the middle $75 \%$ of total tissue thickness for each section. Hence, a forbidden zone of at least 1-2 $\mu \mathrm{m}$ was included at both the top and bottom of each disector, and objects were not counted within the forbidden zone. A motorized stage was used to focus through the full extent of the $z$-axis in each section to ensure that all neurons were counted through the inclusion zone. To correct for shrinkage attributable to dehydration of Nisslstained sections, tissue thickness was measured at three points in each section using a $60 \times$ objective, and the mean thickness was used to calculate the disector height for each section. The mean section thickness was $30 \mu \mathrm{m}^{2}$.

Cells were included in counts if they met the following criteria: (1) cell diameter greater than $8 \mu \mathrm{m}$; (2) polygonal or fusiform rather than round or ovoid soma; (3) clearly visible nucleus and nucleolus within the stereology inclusion boundaries; and (4) the nucleolus did not touch the exclusion boundaries. These parameters were chosen to exclude nonneuronal cells (Pakkenberg and Gunderson, 1997; Simic et al., 1997). In the present study, we confirmed that the $8 \mu \mathrm{m}$ cutoff size enriched neuronal counts without excluding shrunken neurons, as follows: stereological methods were used to measure cell number and size for all cells in area 46 and area $8 \mathrm{~A}$ in all subjects. The results were used to construct histograms with a bin size of $1 \mu \mathrm{m}$ on the $x$-axis and the number of cells of that size on the $y$-axis. The histograms were all strongly bimodal, with a local peak $<8 \mu \mathrm{m}$, a second local peak $>8 \mu \mathrm{m}$, together with a local minimum at $8 \mu \mathrm{m}$. Notably, all cells $<8 \mu \mathrm{m}$ exhibited glial morphology (round soma, no distinguishable nucleolus), whereas cells larger than $8 \mu \mathrm{m}$ displayed typical neuronal morphology (pyramidal morphology, nucleolus visible). Total cell numbers $>8 \mu \mathrm{m}$ in size, and smaller than $8 \mu \mathrm{m}$ in size, were then statistically compared between aged and young groups.

The distance between sections used for quantification and the size and spacing between counting frames were set to achieve a coefficient of error of $<5 \%$ (Gunderson, 1987). In area 46 in young adult animals, every 24 th section was used for quantification; the mean \pm SEM number of sections was $9.00 \pm 0.69$ (minimum, 6; maximum, 11). In area 46 in aged monkeys, every 18th section was used for analysis; the mean \pm SEM number of sections was $11.00 \pm 0.63$ (minimum, 9; maximum, 13). Every 12 th section was used for quantification in area $8 \mathrm{~A}$. The mean number of sections analyzed in area $8 \mathrm{~A}$ in young adult monkeys was $5.1 \pm 0.5$ (minimum, 4 ; maximum, 7 ) and in aged subjects was $5.0 \pm 0.5$ (minimum, 4 ; maximum, 7).

Cytoarchitectonic boundaries for areas 46 and $8 \mathrm{~A}$ were outlined at low power $(4 \times$ objective) using the criteria described above in the anatomical boundaries section, and neurons were then sampled in the indicated layers separately using the pseudorandom sampling scheme of the stereology program under a high-power, high-numerical aperture (1.4) oil $(60 \times)$ objective. Careful inspection indicated that the Nissl stain penetrated the full thickness of each section used for stereological analysis.

Statistics. The total number of neurons and cortical volume were reported for each animal by the stereology program. Group means were computed and compared by two-tailed Student's $t$ test. The null hypothesis in this and all other comparisons was rejected if $p>0.05$.

Cholinergic neuron anatomical boundaries. Anatomical boundaries, as described previously (Mesulam et al., 1983; Smith et al., 1999), were used to delineate $\mathrm{Ch} 4 \mathrm{a}$ and $\mathrm{Ch} 4 \mathrm{i}$. Ch4a and Ch4i are both ventral to the globus 
pallidus. In addition, both $\mathrm{Ch} 4 \mathrm{a}$ and $\mathrm{Ch} 4 \mathrm{i}$ are bounded ventrally by the Ch3 cell group, which contains neurons that are fusiform or oval in morphology, with a long axis that is parallel to the ventral surface of the brain. The rostral extent of Ch4a is limited by the Ch2 cell group, in which neurons are also fusiform or oval in morphology, with the long axis of cells parallel to the ventral surface of the brain. Ch4a continues in a caudal direction until the ansa peduncularis begins to penetrate Ch4. This marks the caudal border of Ch4a and the rostral limit of Ch4i. The presence of the ansa peduncularis is the defining feature of Ch4i: Ch4i continues caudally until the ansa peduncularis completes its passage through $\mathrm{Ch} 4$ and the cholinergic neurons merge into a single group of neurons (Ch4p) that is more ventral and lateral than Ch4i.

Cholinergic neuron stereology. The number and size of cholinergic neurons in anterior and intermediate subdivisions of Ch4 (Ch4a and Ch4i, respectively) were quantified in sections containing basal forebrain that had been immunolabeled for p75, the low-affinity neurotrophin receptor. (Ch4p was not quantified because of the relative paucity of projections from this subregion to frontal cortex.) p 75 colocalizes with $95 \%$ of neurons immunolabeled for choline acetyltransferase in the basal forebrain (Kordower et al., 1988) and does not label other cell types in this brain region. Subjects and tissue preparation are as described above. Every sixth section was processed for p75 immunoreactivity using a monoclonal antibody raised against p75 (monoclonal hybridoma cell line generated by M. Bothwell, University of Washington, Seattle, WA) at a dilution of 1:100. Labeled neurons were visualized using a biotinylated secondary antibody (Jackson ImmunoResearch, West Grove, PA) at a dilution of 1:500, an avidin-biotin complex (Vector Laboratories, Burlingame, CA) and diaminobenzidine. Once again, the number of immunopositive neurons in $\mathrm{Ch} 4 \mathrm{a}$ and $\mathrm{Ch} 4 \mathrm{i}$ was quantified using the optical fractionator method (West et al., 1996; Long et al., 1999). Ch4a and Ch4i were outlined at low power $(4 \times$ objective), and quantification was performed at high power $(60 \times$ oil objective). Cells were included in neuronal counts in Ch4a and Ch4i if they met the following criteria: (1) they were immunopositive for $\mathrm{p} 75$; $(2)$ the cell body was within the counting frame (or touched the inclusion boundary) but did not touch the exclusion boundary; and (3) the cell nucleus was best in focus within the inclusion volume. Careful inspection indicated that the 75 label penetrated the full thickness of each section used for stereological analysis. All other aspects of stereology and statistical analysis were as discussed above for quantification of the number of frontal cortical neurons. As noted above, the mean thickness of each section was measured, and cell objects (nuclei) were counted through the middle $75 \%$ of each section, leaving an exclusion zone of $1-2 \mu \mathrm{m}$ at the top and bottom of each frame $(12.5 \%$ exclusion zone on the top and bottom of each section). Every 12th section was used for quantification through Ch4; the mean \pm SEM number of sections quantified in young monkeys in Ch4a was $5.89 \pm 0.25$ (minimum, 5; maximum, 7) and in aged monkeys was $5.40 \pm 0.56$ (minimum, 5 ; maximum, 8 ). The mean \pm SEM number of sections quantified in young monkeys in Ch4i was $8.05 \pm 0.55$ (minimum, 6; maximum, 9) and in aged monkeys was $7.75 \pm 0.48$ (minimum, 9; maximum, 7).

Staining and quantification of cholinergic innervation of cortex. Acetylcholinesterase (AChE) staining was performed using a modified Tago method (Di Patre et al., 1993) on a series of adjacent free-floating sections spaced $240 \mu \mathrm{m}$ apart. Sections were washed briefly in $0.05 \mathrm{M}$ Tris-maleate buffer, pH 5.7, incubated for $10 \mathrm{~min}$ in Tris-maleate buffer containing 6 $\mu \mathrm{g} / \mathrm{ml}$ promethazine, and washed two additional times in Tris-maleate buffer. Sections were incubated for $30 \mathrm{~min}$ in a $32.5 \mathrm{~mm}$ Tris-maleate buffer solution containing $5 \mathrm{~mm}$ sodium citrate, $3 \mathrm{~mm}$ cupric sulfate, 0.5 mм potassiom ferrocynide, and $0.52 \mathrm{mg} / \mathrm{ml}$ acetylthiocholine iodide and then rinsed five times in $50 \mathrm{~mm}$ Tris- $\mathrm{HCl}, \mathrm{pH}$ 7.6. Sections were incubated for $5 \mathrm{~min}$ in $50 \mathrm{~mm}$ Tris- $\mathrm{HCl}$ containing $0.25 \mathrm{mg} / \mathrm{ml}$ diaminobenzidine tetrahydrochloride and $3 \mathrm{mg} / \mathrm{ml}$ nickel ammonium sulfate. Hydrogen peroxide $(0.006 \%$ final concentration) was added, and sections were allowed to incubate for 2-3 more minutes. The reaction was stopped by washing sections three to four times in $50 \mathrm{~mm}$ Tris- $\mathrm{HCl}$ buffer.

An intersect analysis was used to obtain a quantitative estimate of cholinergic axon density in areas $8 \mathrm{~A}$ and 46 , using standardized methods developed by Geula and Mesulam (1996). This method was chosen be- cause it is relatively insensitive to intersubject variability in AChE staining intensity and is thought to reliably reflect axon density (Geula and Mesulam, 1996; Conner et al., 2001, 2003). Briefly, very high resolution digital images of AChE-stained, $40-\mu \mathrm{m}$-thick sections were captured from an Olympus Optical AX-70 microscope at $360 \times$ magnification (600 $\times$ for hippocampus) with high numerical aperture optics using a digital Spot camera (Diagnostics Instruments, Sterling Heights, MI) with a computer interface. Images were displayed on a high-resolution Sony (Tokyo, Japan) monitor, and a $6 \times 6 \mu \mathrm{m}$ grid $(175 \times 175 \mu \mathrm{m}$ for $360 \times)$ was superimposed on each quantification frame using Adobe Photoshop (Adobe Systems, San Jose, CA). The number of AChE-stained axons intersecting all gridlines in the field was quantified and summed in each image. This method of analysis was chosen because it is capable of quantifying cholinergic fiber numbers, independent of the intensity of the AChE staining intensity (Geula and Mesulam, 1996; Conner et al., 2003). Four fields per animal were quantified in this manner from each region of area $8 \mathrm{~A}$ and 46 that was sampled for neuron counts (see above). Comparable sections were chosen from each experimental subject using fiduciary landmarks by an investigator blinded to group identity. The AChE stain penetrated the full thickness of each cortical section.

\section{Results}

Neuronal number and morphology were examined using stereological methods in prefrontal cortex in aged $(n=6)$ and young $(n=7)$ rhesus monkeys. A subset of these monkeys (aged, $n=3$; young, $n=4$ ) had been behaviorally characterized on a DR test of working memory that is sensitive to the functional integrity of prefrontal cortex (Bauer and Fuster, 1976; Levy and GoldmanRakic, 1999). Accurate performance in this task required subjects to remember which location in a manual test apparatus was baited with a food reward before a retention interval (Eberling et al., 1997). A repeated measures ANOVA, using performance across memory delays of 5-120 sec as a within-subject factor revealed significant main effects of age $\left(F_{(1,6)}=23.1 ; p<0.005\right)$ and delay $\left(F_{(5,30)}=5.2 ; p<0.005\right)$ on task accuracy. The age $\times$ delay interaction was also significant $\left(F_{(5,30)}=2.7 ; p<0.05\right)$, consistent with previous reports (O'Donnell et al., 1999). Thus, aged monkeys in this study were significantly impaired on choice accuracy relative to the young monkeys and exhibited a larger behavioral deficit at longer delay periods. Notably, however, aged subjects scored normally at short delays of $0-5 \mathrm{sec}$ compared with young monkeys, suggesting that aged monkeys retained the ability to select appropriate responses (Fig. 1). Specifically, there was no group difference in the mean number of trials required to reach criterion performance at the 0 and $1 \mathrm{sec}$ delays (90\% correct; $p>0.05$ ). Similarly, at a short delay of $5 \mathrm{sec}$, aged and young monkeys scored comparably: aged monkeys, $86.3 \pm 3.5 \%$ correct, and young monkeys, $91.9 \pm 0.5 \%$ correct $(p>0.05)$. However, aged monkeys exhibited significant impairment compared with young adult monkeys at delays of $10 \mathrm{sec}$ and longer ( $p$ values $<0.05$ ) (Fig. 1), suggesting that the ability to maintain representations in working memory across longer retention intervals declines with age.

Neuronal number was then quantified using stereological methods in thionin-stained sections from two cytoarchitectonically defined regions of prefrontal cortex implicated previously in working memory, areas 8A and 46 (Fig. 2) (Funahashi et al., 1993; Fiez et al., 1996; Owen et al., 1999; Quintana and Fuster, 1999; Levy and Goldman-Rakic, 2000; Rowe et al., 2000; Fuster, 2002). In each region, quantification was performed separately for superficial (layers I-IV) and deep layers (V and VI) on the basis of similarities in the projection patterns and operations of these respective layers. Stereological quantification revealed that neuronal number was preserved in area 46 in aged monkeys. The mean \pm SD total neuronal number across all layers of area 46 was 


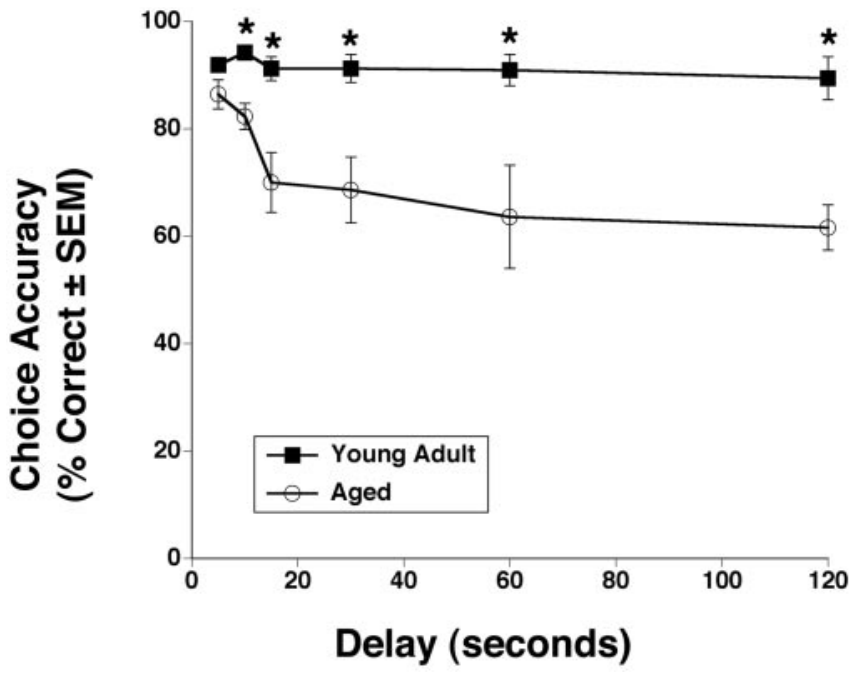

Figure 1. Working memory performance on delayed response task. Performance of aged monkeys did not differ significantly from young adult monkeys at delays of 5 sec and less, but significant impairments were present at each delay period of 10 sec and longer.

$30.09 \pm 2.75 \times 10^{6}$ in young adult monkeys and $28.92 \pm 2.77 \times$ $10^{6}$ in aged monkeys $(p=0.46)$. Subdivided by layer groupings, young adult and aged monkeys displayed similar neuronal numbers in layers I-IV and in layers V-VI of area 46. In layers I-IV, the mean \pm SD neuronal number in area 46 in young adult monkeys was $19.48 \pm 1.73 \times 10^{6}$ and was $18.90 \pm 1.40 \times 10^{6}$ in aged monkeys ( $p=0.53$ ) (Fig. 2). In layers V-VI of area 46, young adult monkeys exhibited a mean neuronal number of $10.61 \pm 1.51 \times 10^{6}$, and aged monkeys had a mean of $10.02 \pm$ $1.41 \times 10^{6}$ neurons $(p=0.48)$ (Fig. 2$)$.

In contrast, a significant $32 \pm 11 \%$ reduction in neuronal number was observed in aged monkeys across all layers of area $8 \mathrm{~A}$ compared with young monkeys, and this decline correlated significantly with impaired working memory performance in the respective groups of animals $\left(R^{2}=0.81 ; p<0.01\right)$. The mean \pm SD total number of neurons in area $8 \mathrm{~A}$ in young adult monkeys was $14.09 \pm 1.63 \times 10^{6}$, whereas aged monkeys exhibited a mean of $9.64 \pm 1.02 \times 10^{6}$ neurons $(p<0.0001)$. Neuronal loss in area $8 \mathrm{~A}$ was evident in aged subjects in both layers I-IV $(38 \pm 10 \%$, from a mean of $8.91 \pm 0.80 \times 10^{6}$ neurons in young adult monkeys to a mean of $5.60 \pm 0.73 \times 10^{6}$ neurons in aged monkeys; $p<0.0001)$ (Fig. 2) and layers V-VI ( $22 \pm 15 \%$, from a mean of $5.19 \pm 0.98 \times 10^{6}$ neurons in young adult monkeys to a mean of $4.06 \pm 0.53 \times 10^{6}$ neurons in aged monkeys; $p<0.05$ ) (Fig. 2). Neuronal number, therefore, was significantly reduced in one subregion of prefrontal cortex associated with working memory, area $8 \mathrm{~A}$, but was maintained in an adjoining prefrontal region contributing to working memory, area 46.

To determine whether the observed reduction in cell number in area $8 \mathrm{~A}$ represented true cell death rather than cell shrinkage (atrophy), the number of thionin-stained cells in area $8 \mathrm{~A}$ was quantified as a function of size. There was no significant increase in the percentage of small cells $(<8 \mu \mathrm{m}$ diameter) in aged subjects. In fact, the proportion of small neurons $(<8 \mu \mathrm{m}$ diameter $)$ was slightly greater in young monkeys $(44 \pm 6 \%)$ than in aged subjects $(34 \pm 5 \% ; p>0.05)$. Furthermore, there was no significant difference in mean overall size across all cells when comparing young adult and aged monkeys $(p=0.77)$. Thus, cell shrinkage below the limits of detection did not account for reductions in cell number in area $8 \mathrm{~A}$.
Memory deficits in normal aging have also been attributed to disruption of cholinergic function (Kadar et al., 1990), and degeneration of cholinergic neurons that project to cortex has been reported previously in aged humans (de Lacalle et al., 1991) and nonhuman primates (Smith et al., 1999). Cholinergic innervation of dorsolateral prefrontal cortex was examined by measuring the density of cholinergic axons in sections histochemically stained for AChE using methods established by Mesulam and colleagues (Mesulam et al., 1983; Conner et al., 2001, 2003). Alterations in cholinergic axon density with age exhibited a pattern consistent with changes in neuronal number in prefrontal areas 46 and $8 \mathrm{~A}$ (Fig. 3). In area 46, in which neuronal number was preserved with aging, cholinergic axon density was normal (Fig. 3 ). However, in area $8 \mathrm{~A}$, aged subjects exhibited a significant $23 \pm$ $5 \%$ reduction in the density of cholinergic axons in layers I-IV, from a mean $\pm \mathrm{SD}$ of $0.53 \pm 0.10 \times 10^{6}$ fibers $/ \mathrm{mm}^{3}$ in young adult subjects to a mean of $0.40 \pm 0.03 \times 10^{6}$ in aged monkeys $(p<0.05)$ (Fig. 3). Layers I-IV of neocortex contain the primary target of corticocortical and thalamocortical projections. No significant reduction in cholinergic inputs to layers $\mathrm{V}$ and VI of area 8A was detected: cholinergic fiber density was $0.40 \pm 0.09 \times 10^{6}$ fibers $/ \mathrm{mm}^{3}$ in young adult monkeys and $0.38 \pm 0.07 \times 10^{6}$ fibers $/ \mathrm{mm}^{3}$ in aged subjects $(p=0.60)$. Layers V-VI of cortex provide the primary output projections to other brain regions. Changes in cortical volume were not artifactually responsible for reductions in cholinergic axon density in any region, because the volume of prefrontal areas, measured stereologically, did not significantly differ between young adult and aged monkeys $(p=$ 0.97 in area $46 ; p=0.79$ in area $8 \mathrm{~A}$ ). Thus, cholinergic innervation was significantly reduced only where the most pronounced loss of cortical neurons was observed, in layers I-IV of area 8A.

Reduced cholinergic innervation in area $8 \mathrm{~A}$ may reflect degeneration of cholinergic neurons that project to cortex. The number of cholinergic neurons that innervate prefrontal areas 46 and $8 \mathrm{~A}$ was therefore examined using stereological methods in sections immunolabeled for the low-affinity neurotrophin receptor (p75), a specific marker of basal forebrain cholinergic neurons in this brain region (Kordower et al., 1988). The largest portion of cholinergic innervation of area 46 arises from the anterior division of the nucleus basalis of Meynert (designated $\mathrm{Ch} 4 \mathrm{a}$ ), whereas the intermediate division of the nucleus basalis of Meynert (designated Ch4i) provides the majority of cholinergic innervation to area 8A (Mesulam et al., 1983). In Ch4a, there was a trend toward a slight increase in number of immunolabeled neurons in aged monkeys: the mean \pm SD number of immunolabeled neurons in Ch4a in young adult monkeys was $5.98 \pm$ $0.90 \times 10^{4}$ versus $7.24 \pm 1.35 \times 10^{4}$ in aged monkeys $(p=0.07)$ (Fig. 4). There was no significant difference in the size of Ch4a neurons between young $\left(460 \pm 41 \mu \mathrm{m}^{2}\right)$ and aged $(436 \pm 17$ $\left.\mu \mathrm{m}^{2} ; p=0.21\right)$ monkeys. In contrast, the intermediate component of $\mathrm{Ch} 4$, which originates inputs to area $8 \mathrm{~A}$, exhibited reductions in the number of p75-immunolabeled cells, consistent with patterns of cell loss in area $8 \mathrm{~A}$. There was a significant $50 \pm 6 \%$ reduction in the number of immunolabeled cholinergic neuronal somata within Ch4i in aged subjects, from a mean \pm SD of $5.23 \pm$ $0.97 \times 10^{4}$ in young adult monkeys to a mean of $2.59 \pm 0.39 \times$ $10^{4}$ in aged subjects $(p<0.0001)$ (Fig. 4$)$. Immunolabeled neurons within $\mathrm{Ch} 4 \mathrm{i}$ also exhibited a significant $12 \pm 3 \%$ decrease in cell size in aged subjects. The mean \pm SD cross-sectional area in young adult monkeys was $513 \pm 44 \mu \mathrm{m}^{2}$, whereas in aged monkeys the mean size was $451 \pm 33 \mu \mathrm{m}^{2}(p<0.05)$ (Fig. 4). Previous results (Smith et al., 1999) have demonstrated that a reduction in the number of immunolabeled neurons in Ch4 in the aged 
A
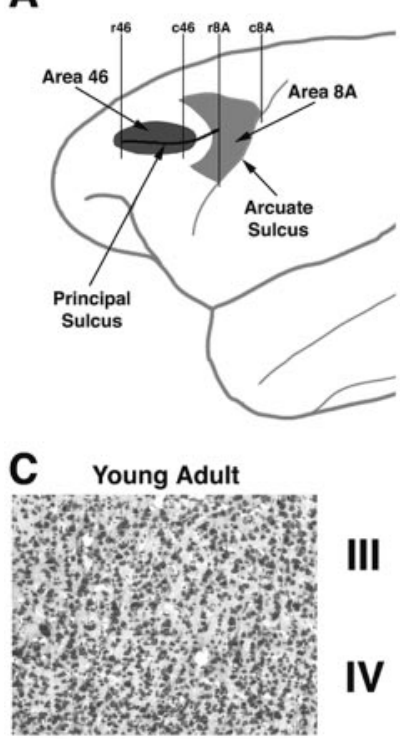

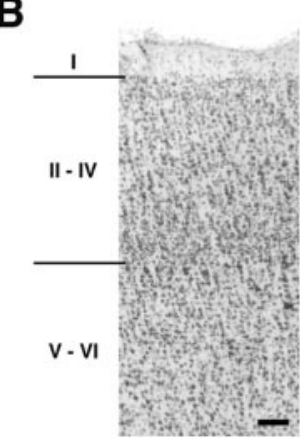

B

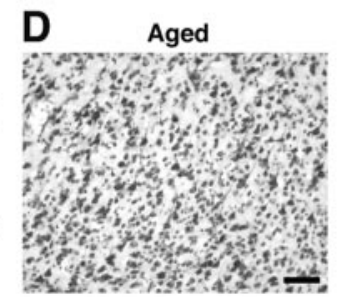

E

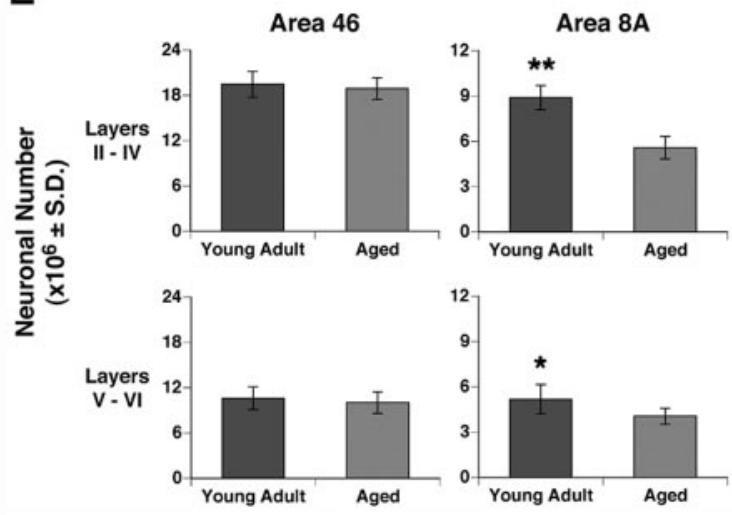

Figure 2. Quantification of neuronal number and morphology in dorsolateral prefrontal cortex. A, Lateral surface of prefrontal cortex indicating area 46 (dark shading) and area $8 \mathrm{~A}$ (light shading), in which neuronal number was quantified. Vertical lines indicate sterological boundaries. Lines marked $r 46$ and c46 delineate rostral and caudal limits of area 46, and lines r8A and c8A denote rostral and caudal boundaries of area $8 A$. B, Thionin-stained coronal section of prefrontal cortex, showing grouping of layers II-IV and V-VI for quantification, on the basis of projection patterns. Scale bar, $150 \mu \mathrm{m}$. C, Higher magnification of thionin-stained sections in layers III-IV of area $8 \mathrm{~A}$ in young adult; $D$, aged monkey, suggesting reduced cell density in aged monkey. Scale bar: C, D, $70 \mu \mathrm{m} . E$, Stereological quantification of neuronal number in area 46 and area $8 \mathrm{~A}$. In area 46 , neuronal number was preserved in aged monkeys. In contrast, highly significant reduction in neuronal number was observed in layers II-IV ( $p<0.0001)$ and $\mathrm{V}-\mathrm{VI}$ in area $8 \mathrm{~A}$ of aged monkeys $(p<0.05)$.
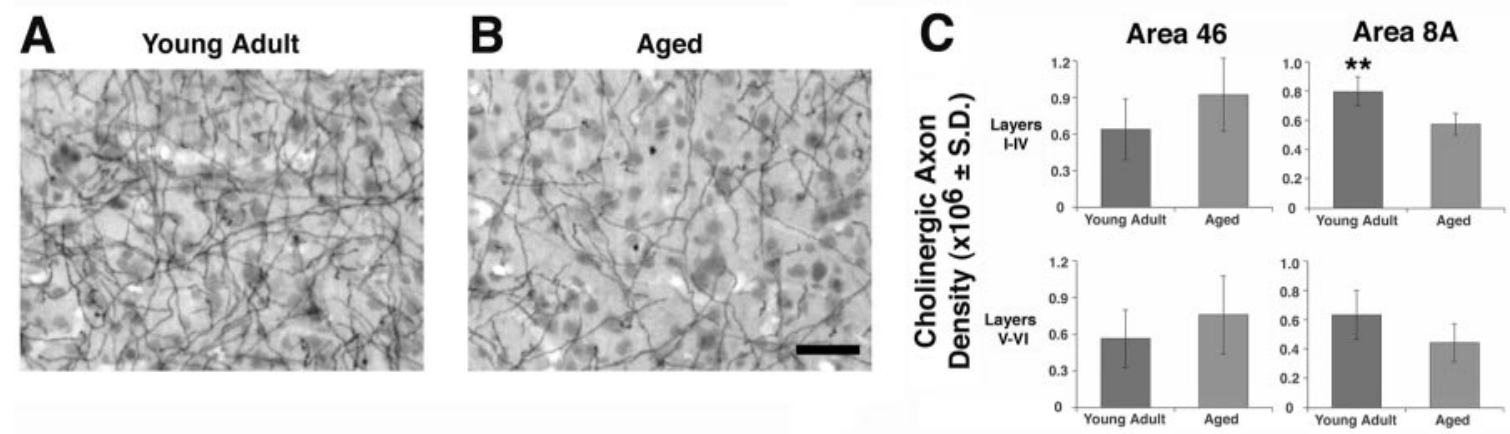

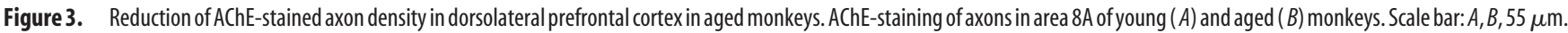
C, Quantification of AChE-stained axon density shows significant reductions in layers I-IV of area $8 \mathrm{~A}(p<0.05)$, in which Nissl-stained neurons are also lost. In contrast, AChE-stained axons are preserved in area 46, in which the number of Nissl-stained neurons was also preserved. Reductions in cortical volume do not account for these changes (see Results).

primate reflects cellular atrophy rather than death. Thus, atrophy of basal forebrain cholinergic neurons was observed only in a division of the basal forebrain that projects to an area of prefrontal cortex in which substantial neuronal loss occurred. Furthermore, the number of immunolabeled neurons in Ch4i correlated significantly with the number of cortical neurons in layers I-IV of area $8 \mathrm{~A}\left(R^{2}=0.76 ; p<0.0001\right)$.

\section{Discussion}

Findings of this study demonstrate significant reductions of cell number in cortical regions involved in age-related memory decline, together with extensive transneuronal degeneration of subcortical neurons that project to these cortical regions. This loss is highly focal and selective: adjacent cortical regions that contribute to similar memory functions are preserved, together with their subcortical inputs. Thus, compared with young adult mon- keys, area $8 \mathrm{~A}$ of aged primates exhibited a $38 \%$ loss of thioninstained neurons, a $23 \%$ reduction in cholinergic axon terminals in superficial cortical layers, and a 50\% atrophy of cholinergic neurons in a subcortical nucleus that innervates this cortical area. Area $8 \mathrm{~A}$ has been implicated in the working memory task on which the aged monkeys were impaired (Funahashi et al., 1993; Fiez et al., 1996; Quintana and Fuster, 1999; Levy and GoldmanRakic, 2000; Rowe et al., 2000; Fuster, 2002). However, an adjoining region of cortex that also contributes to working memory, area 46, exhibited anatomical sparing with no reduction in cortical cell number, size, or inputs from cholinergic systems. The reduction of cortical neuron number in area $8 \mathrm{~A}$ is not an artifact of cell shrinkage: the proportion of small cells did not increase in aged compared with young monkeys, nor did mean cortical neuron size differ among young and aged subjects. Thus, highly focal cell loss occurs in the cortex with aging and is accompanied by 
transneuronal degeneration that can substantially extend the region of age-related atrophy beyond the immediate region of cortical involvement.

Aged monkeys in this study showed no impairment in selecting correct responses at short delays on a working memory task but did exhibit significant impairment in recalling those responses at longer delays. Does the observed anatomical pattern of cell sparing in area 46 and cell loss in area $8 \mathrm{~A}$ correlate with the behavioral sparing at short delays and impairment at longer delays? A previous functional magnetic resonance imaging study in humans reported that selection, but not maintenance, of working memory was associated with activation of prefrontal cortical area 46, whereas activation of prefrontal area 8 and the infraparietal cortex was associated with memory maintenance (Rowe et al., 2000). This pattern of behavioral performance corresponds with the observed patterns of cell loss and sparing in our study. However, several lesion and electrophysiological studies in non-human primates have not demonstrated this pattern of functional segregation in the prefrontal cortex (Funahashi et al., 1993; Quintana and Fuster, 1999; Levy and Goldman-Rakic, 2000; Fuster, 2002), suggesting instead that area 46 has an active role in the delayed component of working memory on which our subjects were impaired. Because this study was not prospectively designed to examine the functional parcellation of prefrontal cortex in working memory tasks, further conclusions in this respect are not warranted. Nonetheless, because areas $8 \mathrm{~A}$ and 46 are required to perform the working memory task of this study, one can conclude that loss of cells and their inputs in area $8 \mathrm{~A}$ likely contribute to the decline of working memory with age.

The highly focal nature of this cellular and transcellular degeneration probably accounts for the failure of previous studies to identify significant cell loss as a substrate of age-related cognitive decline. Previous investigations of cell number in the cortex and hippocampus of aged primates concluded that the brain is essentially spared of neuronal loss with aging (Walker et al., 1988; Vincent et al., 1989; Ahmad and Spear, 1993; Peters et al., 1994; Gazzaley et al., 1997; Kemper et al., 1997; Kim et al., 1997; Hof et al., 2000; Peters, 2002; Keuker et al., 2003). However, the lack of stereological methodology in some studies may have led to erroneous conclusions because of age-related changes in brain size, volume, or neuronal packing density that have been described in several reports (Walker et al., 1988; Vincent et al., 1989; Peters et al., 1994; Kemper et al., 1997; Kim et al., 1997; Peters, 2002). Other studies used stereological methods but sampled broader cortical regions rather than focal functional subdivisions (Kemper et al., 1997; Hof et al., 2000; Keuker et al., 2003).

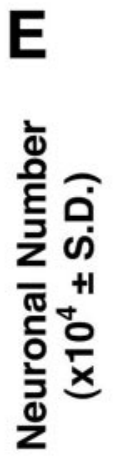

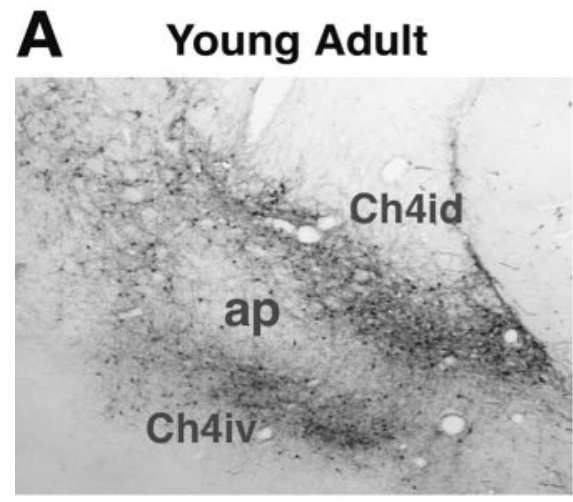
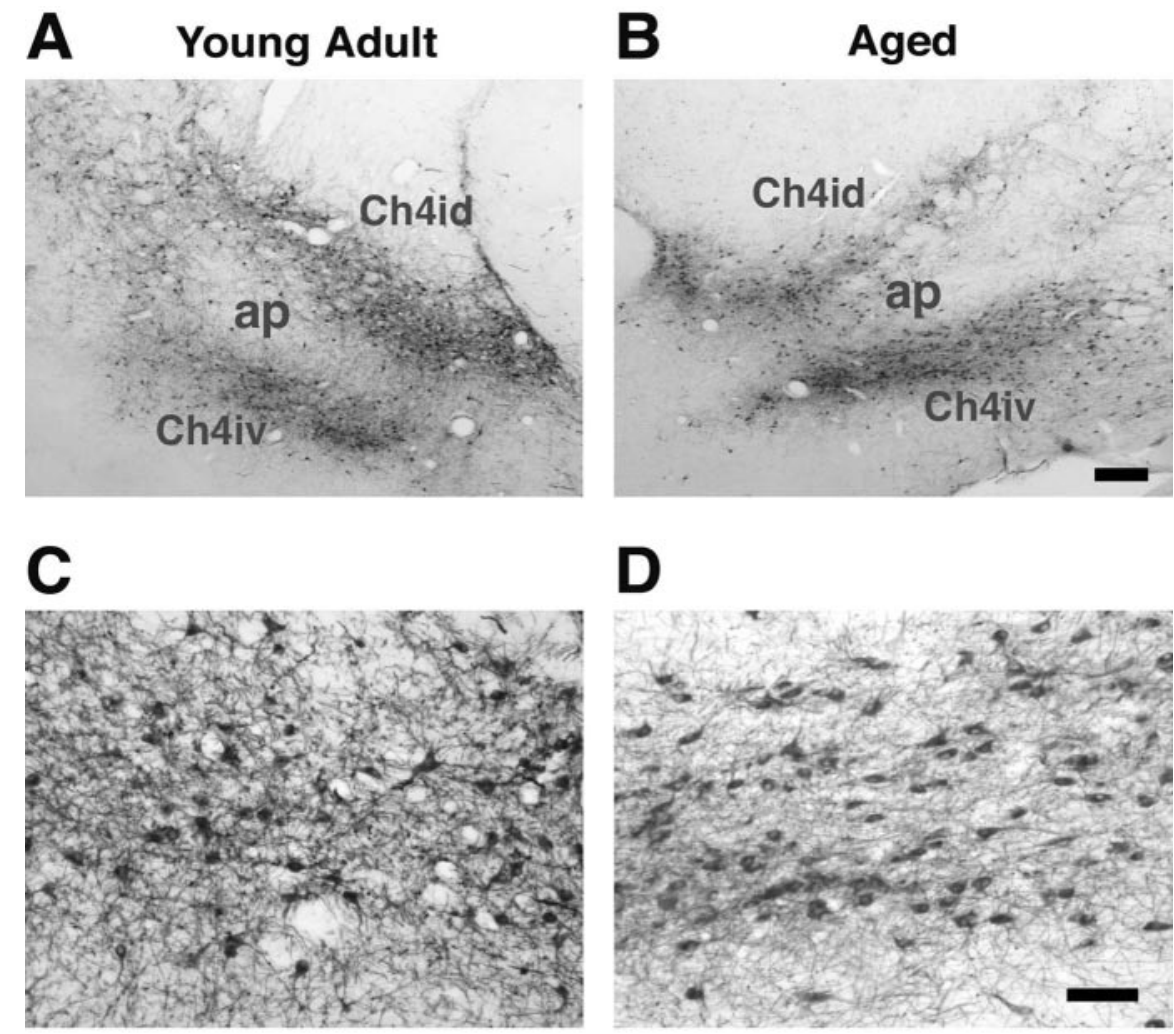

Ch4i

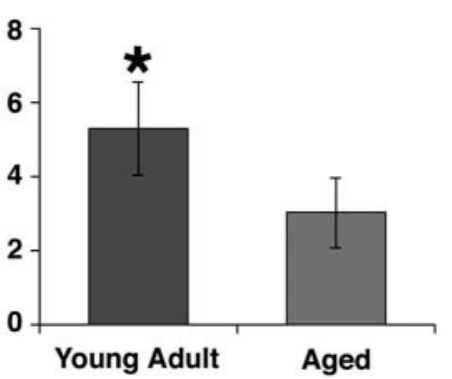

Ch4a

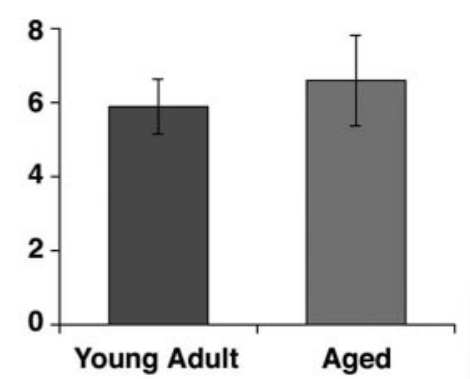

Figure 4. p75-labeled cholinergic neuronal numbers are selectively reduced in aged monkeys. Low-magnification views of representative sections from a young adult $(A)$ and an aged $(B)$ monkey demonstrate distribution of immunolabeled neurons in the intermediate division of the basal forebrain (Ch4i). ap, Ansa pdenuclaris; Ch4id, intermediodorsal component of Ch4 region; Ch4iv, intermedioventral component of Ch4 region. Scale bar: $A, B, 270 \mu \mathrm{m}$. Higher-magnification views from a young adult $(C)$ of the number of p75-labeled neurons revealed significant reductions in Ch4i ( $p<0.0001)$, the division of the cholinergic basal forebrain that projects to the area of prefrontal cortex in which neuronal loss occurred (area 8A). Ch4a, which innervates the area of prefrontal cortex in which neuronal number was preserved, displayed no reduction $(p>0.05)$.

Indeed, the examination of overlapping, broader regions of cortex may lead to a loss of sensitivity in identifying focal regions of cell loss during the course of age-related decline in cognition. Although some brain regions do in fact exhibit cell sparing with aging, including thalamic nuclei (Ahmad and Spear, 1993) or area 46 as shown in the present study, other adjoining regions (e.g., area 8A) clearly exhibit cell loss. Thus, future studies of age-related brain dysfunction would benefit from examination of very focal and well defined functional subdivisions of neural circuitry, when possible.

It is notable that both cortical neurons and their inputs from subcortical regions degenerated in aged, cognitively impaired monkeys. Cholinergic innervation of prefrontal cortex primarily 
arises from the Ch4 group of neurons examined in this study, although a small component also arises from the hypothalamus, a region that we did not examine. Basal forebrain cholinergic neurons exert an important role in modulating cortical plasticity (Kilgard and Merzenich, 1998; Conner et al., 2003). Cholinergic neurons degenerate if deprived of nerve growth factor (NGF) (Tuszynski et al., 1990; Liberini et al., 1994) and remain sensitive to NGF even in the aged primate (Kordower et al., 1994; Smith et al., 1999; Conner et al., 2001). Therefore, declining trophic support from target cells in superficial layers of prefrontal area $8 \mathrm{~A}$ could cause degeneration of cholinergic neurons in Ch4i. Alternatively, degeneration of cholinergic basal forebrain neurons could cause trans-synaptic changes that ultimately result in loss of cortical neurons (Unger and Schmidt, 1994; Zhang et al., 1998).

This study was not prospectively designed or powered to examine gender-related effects on age-related changes in cognition or cellular parameters, and estrogen levels were not measured in the experimental subjects. Thus, conclusions regarding genderrelated effects cannot be made. However, the performance of the two aged female monkeys was not worse than that of the two aged monkeys on the delayed response task, nor were cell numbers suggestive of a gender difference in the cortex or $\mathrm{Ch} 4$ region (data not shown) in these subjects.

Together with alterations in neuronal gene expression (Colombo et al., 1997; Guarente and Kenyon, 2000; Murphy et al., 2003), intracellular transport, neurotransmitter systems-receptors (Arnsten et al., 1995; Gazzaley et al., 1997; Hof et al., 2002), synapses (Tigges et al., 1995; Smith et al., 2000), dendrites-spines (Uemura, 1985a,b; Peters et al., 1994; Hayashi et al., 2001; Page et al., 2002), electrophysiological mechanisms (Tanila et al., 1997), astroglial (Sloane et al., 2000), and white matter changes (Peters, 2002), a more comprehensive picture of mechanisms underlying age-related neural degeneration emerges. The mechanism of this degeneration is likely multifactorial and varies, depending on the brain region affected.

\section{Appendix}

As noted above, three aged monkeys in this study were behaviorally tested. Twelve months after completion of behavioral testing, these three subjects received injections of primary autologous fibroblasts genetically modified to express the inert reporter gene $\beta$-gal into five evenly spaced sites covering the rostral-to-caudal extent of the Ch4i region, thereby serving as control subjects in another study examining growth factor delivery to other sets of monkeys (Smith et al., 1999). Control fibroblasts (10 $\mu \mathrm{l})$ were injected into each site. Aged subjects included in the present study were not exposed to growth factors. Previously, we reported that these control fibroblast grafts to the Ch4i region had no effect on either the number or morphology of immunolabeled cholinergic basal forebrain neurons (Smith et al., 1999) or the density of their projections to cortex (Conner et al., 2001) when compared with aged-matched non-operated monkeys. To extend and confirm these results in the present study, we compared the following: (1) the number of immunolabeled cholinergic basal forebrain neurons, (2) the density of cholinergic projections to prefrontal cortex, and (3) the number of neurons in prefrontal cortex in groups of aged control fibroblast-grafted $(n=3)$ versus age-matched non-operated $(n=3)$ monkeys. There were no differences in any measured parameter between these groups. In aged monkeys (graft recipient mean age, $24.3 \pm 2.0$ years; unoperated mean age, $26.1 \pm 1.7$ years), control grafts did not alter any of the following: (1) the mean \pm SD number of immunolabeled cholinergic basal forebrain neurons in either Ch4i (aged grafted animals, $2.58 \pm 0.50 \times 10^{4}$ neurons; aged unoperated animals, $2.60 \pm 0.36 \times 10^{4}$ neurons; $p=0.95$ ) or Ch4a (aged grafted animals, $6.80 \pm 1.41 \times 10^{4}$ neurons; aged unoperated animals, $7.68 \pm 1.42 \times 10^{4}$ neurons; $\left.p=0.49\right)$; (2) the mean \pm SD density of cholinergic innervation in either area $8 \mathrm{~A}$ (aged grafted animals, $3.94 \pm 0.43 \times 10^{5}$ fibers $/ \mathrm{mm}^{3}$; aged unoperated animals, $4.1 \pm 0.17 \times 10^{5}$ fibers $/ \mathrm{mm}^{3} ; p=0.57$ ) or area 46 (aged grafted animals, $2.91 \pm 1.16 \times 10^{5}$ fibers $/ \mathrm{mm}^{3}$; aged unoperated animals, $2.47 \pm 0.36 \times 10^{5}$ fibers $/ \mathrm{mm}^{3} ; p=0.58$ ); or (3) the mean \pm SD number of cortical neurons in either area $8 \mathrm{~A}$ (aged grafted animals, $10.12 \pm 0.32 \times 10^{6}$ neurons; aged unoperated animals, $9.16 \pm 1.33 \times 10^{6}$ neurons; $p=0.29$ ) or area 46 (aged grafted animals, $29.26 \pm 4.31 \times 10^{6}$ neurons; aged unoperated animals, $28.59 \pm 0.54 \times 10^{6}$ neurons; $p=0.80$ ). Similarly, of the seven young adult monkeys that were subjects in this study, the four that were behaviorally characterized received transduced fibroblast grafts to Ch4i 12 months after completion of behavioral testing. Behavioral testing was conducted as part of a previous study that examined cognitive decline associated with normal aging. After completion of that behavioral study, these young adult monkeys received $10 \mu \mathrm{l}$ suspension grafts of autologous fibroblasts that were genetically modified to produce NGF into five sites of Ch4i, as part of an NGF dosing study in young monkeys. NGF delivery to the intact brains of young animals has been reported previously to have no effect on the number or morphology of immunolabeled cholinergic basal forebrain neurons (Chen and Gage, 1995). To determine whether NGF grafts altered any of the parameters measured in this study, we compared the following: (1) the number of immunolabeled cholinergic basal forebrain neurons, (2) the density of cholinergic projections to prefrontal cortex, and (3) the number of neurons in prefrontal cortex of these four young adult NGF-grafted to three agematched young adult non-operated monkeys. No differences in cell number or morphology were found between these groups. NGF-secreting grafts in young adult monkeys (mean age, $11.4 \pm$ 1.5 years), compared with young nongrafted monkeys (mean age, $10.6 \pm 1.2$ years), did not change any of the following: (1) the mean \pm SD number of immunolabeled cholinergic basal forebrain neurons in either Ch4i (young NGF-grafted animals, $5.29 \pm 1.27 \times 10^{4}$ neurons; young unoperated animals, $4.57 \pm$ $1.24 \times 10^{4}$ neurons; $p=0.45$ ) or Ch4a (young NGF-grafted animals, $5.88 \pm 0.74 \times 10^{4}$ neurons; young unoperated animals, $6.12 \pm 1.25 \times 10^{4}$ neurons; $\left.p=0.77\right)$; (2) the density of cholinergic innervation $( \pm S D)$ in either area $8 \mathrm{~A}$ (young NGF-grafted animals, $5.19 \pm 0.95 \times 10^{4}$ fibers $/ \mathrm{mm}^{3}$; young unoperated animals, $5.33 \pm 1.36 \times 10^{4}$ fibers $/ \mathrm{mm}^{3} ; p=0.88$ ) or area 46 (young NGF-grafted animals, $5.19 \pm 0.95 \times 10^{4}$ fibers $/ \mathrm{mm}^{3}$; young unoperated animals, $5.33 \pm 1.36 \times 10^{4}$ fibers $/ \mathrm{mm}^{3} ; p=0.88$ ); or (3) the mean \pm SD number of cortical neurons in either area $8 \mathrm{~A}$ (young NGF-grafted animals, $14.33 \pm 1.80 \times 10^{6}$ neurons; young unoperated animals, $13.77 \pm 1.71 \times 10^{6}$ neurons; $p=$ 0.70 ) or area 46 (young NGF-grafted animals, $30.10 \pm 3.68 \times 10^{6}$ neurons; young unoperated animals, $30.07 \pm 1.53 \times 10^{6}$ neurons; $p=0.99$ ). To summarize, three of six aged monkeys and four of seven young adult monkeys used in this study were behaviorally characterized. All animals were unoperated and intact throughout behavioral testing. Twelve months after completion of behavioral testing, aged monkeys received autologous grafts of primary $\beta$-gal-producing fibroblasts. These grafts had no effect on any cellular parameter measured. Four of seven young adult monkeys received grafts of autologous NGF-secreting fibroblasts after completion of behavioral testing, and, consistent with pre- 
vious reports, NGF delivery in the young intact brain had no effect on any cellular parameter measured. Thus, grafts placed in monkeys used in this study (1) did not influence behavioral results because behavioral testing was completed before grafts were placed and (2) did not alter any cellular parameter, as noted above.

\section{References}

Ahmad A, Spear PD (1993) Effects of aging on the size, density, and number of rhesus monkey lateral geniculate neurons. J Comp Neurol 334:631-643.

Arnsten AF, Cai JX, Steere JC, Goldman-Rakic PS (1995) Dopamine D2 receptor mechanisms contribute to age-related cognitive decline: the effects of quinpirole on memory and motor performance in monkeys. J Neurosci 15:3429-3439.

Baddeley A (1998) Recent developments in working memory. Curr Opin Neurobiol 8:234-238.

Barbas H (2000) Connections underlying the synthesis of cognition, memory, and emotion in primate prefrontal cortices. Brain Res Bull 52:319-330.

Bauer RH, Fuster JM (1976) Delayed-matching and delayed-response deficit from cooling dorsolateral prefrontal cortex in monkeys. J Comp Physiol Psychol 90:293-302.

Briggs SD, Raz N, Marks W (1999) Age-related deficits in generation and manipulation of mental images: I. The role of sensorimotor speed and working memory. Psychol Aging 14:427-435.

Chen KS, Gage FH (1995) Somatic gene transfer of NGF to the aged brain: Behavioral and morphological amelioration. J Neurosci 15:2819-2825.

Colombo PJ, Wetsel WC, Gallagher M (1997) Spatial memory is related to hippocampal subcellular concentrations of calcium-dependent protein kinase C isoforms in young and aged rats. Proc Natl Acad Sci USA 94:14195-14199.

Conner JM, Darracq MA, Roberts J, Tuszynski MH (2001) Non-tropic actions of neurotrophins: Subcortical NGF gene delivery reverses agerelated degeneration of primate cortical cholinergic innervation. Proc Natl Acad Sci USA 98:1941-1946.

Conner JM, Culberson A, Packowski C, Chiba A, Tuszynski MH (2003) Lesions of the basal forebrain cholinergic system impair task acquisition and abolish cortical plasticity associated with motor skill learning. Neuron 38:819-829.

de Lacalle S, Iraizoz I, Ma Gonzalo L (1991) Differential changes in cell size and number in topographic subdivisions of human basal nucleus in normal aging. Neurosci 43:445-456.

Di Patre PL, Methes CW, Butcher LL (1993) Differential visualization of cholinesterase neuronal somata and fibers by use of modificaitons of acetylcholinesterease pharmacohistochemistry. J Histochem Cytochem 41:129-135.

Eberling JL, Roberts JA, Rapp PR, Tuszynski MH, Jagust WJ (1997) Cerebral glucose metabolism and memory in aged rhesus macaques. Neurobiol Aging 18:437-443.

Fiez JA, Raife EA, Balota DA, Schwarz JP, Raichle ME, Petersen SE (1996) A positron emission tomography study of the short-term maintenance of verbal information. J Neurosci 16:808-822.

Funahashi S, Bruce CJ, Goldman-Rakic PS (1993) Dorsolateral prefrontal lesions and oculomotor delayed-response performance: evidence for mnemonic "scotomas". J Neurosci 13:1479-1497.

Fuster JM (2002) Frontal lobe and cognitive development. J Neurocytol 31:373-385.

Gazzaley AH, Thakker MM, Hof PR, Morrison JH (1997) Preserved number of entorhinal cortex layer II neurons in aged macaque monkeys. Neurobiol Aging 18:549-553.

Geula C, Mesulam MM (1996) Systematic regional variations in the loss of cortical cholinergic fibers in Alzheimer's disease. Cereb Cortex 6:165-177.

Giguere M, Goldman-Rakic PS (1988) Mediodorsal nucleus: areal, laminar, and tangential distribution of afferents and efferents in the frontal lobe of rhesus monkeys. J Comp Neurol 277:195-213.

Grady CL, Craik FI (2000) Changes in memory processing with age. Curr Opin Neurobiol 10:224-231.

Guarente L, Kenyon C (2000) Genetic pathways that regulate ageing in model organisms. Nature 408:255-262.

Gundersen HJ (1988) The nucleator. J Microsc 151 (Pt 1):3-21.

Gunderson HJG (1987) The efficiency of systematic sampling in stereology and its prediction. J Microsc 147:229-263.
Hayashi M, Mistunaga F, Ohira K, Shimizu K (2001) Changes in BDNFimmunoreactive structures in the hippocampal formation of the aged macaque monkey. Brain Res 918:191-196.

Hof PR, Nimchinsky EA, Young WG, Morrison JH (2000) Numbers of meynert and layer IVB cells in area V1: a stereologic analysis in young and aged macaque monkeys. J Comp Neurol 420:113-126.

Hof PR, Duan H, Page TL, Einstein M, Wicinski B, He Y, Erwin JM, Morrison $\mathrm{JH}$ (2002) Age-related changes in GluR2 and NMDAR1 glutamate receptor subunit protein immunoreactivity in corticocortically projecting neurons in macaque and patas monkeys. Brain Res 928:175-186.

Kadar T, Silbermann M, Weissman BA, Levy A (1990) Age-related changes in the cholinergic components within the central nervous system. II. Working memory impairment and its relation to hippocampal muscarinic receptors. Mech Ageing Dev 55:139-149.

Kemper TL, Moss MB, Rosene DL, Killiany RJ (1997) Age-related neuronal loss in the nucleus centralis superior of the rhesus monkey. Acta Neuropathol (Berl) 94:124-130.

Keuker JI, Luiten PG, Fuchs E (2003) Preservation of hippocampal neuron numbers in aged rhesus monkeys. Neurobiol Aging 24:157-165.

Kilgard MP, Merzenich MM (1998) Cortical map reorganization enabled by nucleus basalis activity. Science 279:1714-1718.

Kim CB, Pier LP, Spear PD (1997) Effects of aging on numbers and sizes of neurons in histochemically defined subregions of monkey striate cortex. Anat Rec 247:119-128.

Kordower JH, Bartus RT, Bothwell M, Schatteman G, Gash DM (1988) Nerve growth factor receptor immunoreactivity in the non-human primate (Cebus apella): distribution, morphology, and colocalization with cholinergic enzymes. J Comp Neurol 277:465-486.

Kordower JH, Winn SR, Liu Y-T, Mufson EJ, Sladek JR, Hammang JP, Baetge EE, Emerich DF (1994) The aged monkey basal forebrain: Rescue and sprouting of axotomized basal forebrain neurons after grafts of encapsulated cells secreting human nerve growth factor. Proc Natl Acad Sci USA 91:10898-10902.

Krettek JE, Price JL (1977) The cortical projections of the mediodorsal nucleus and adjacent thalamic nuclei in the rat. J Comp Neurol 171:157-191.

Levy R, Goldman-Rakic PS (1999) Association of storage and processing functions in the dorsolateral prefrontal cortex of the nonhuman primate. J Neurosci 19:5149-5158.

Levy R, Goldman-Rakic PS (2000) Segregation of working memory functions within the dorsolateral prefrontal cortex. Exp Brain Res 133:23-32.

Liberini P, Pioro EP, Maysinger D, Cuello AC (1994) Neocortical infarction in subhuman primates leads to restricted morphological damage of the cholinergic neurons in the nucleus basalis of Meynert. Brain Res 648:1-8.

Light LL, Anderson PA (1985) Working-memory capacity, age, and memory for discourse. J Gerontol 40:737-747.

Long JM, Mouton PR, Jucker M, Ingram DK (1999) What counts in brain aging? Design-based stereological analysis of cell number. J Gerontol A Biol Sci Med Sci 54:B407-417.

Mesulam MM, Mufson EJ, Levey AI, Wainer BH (1983) Cholinergic innervation of cortex by the basal forebrain: cytochemistry and cortical connections of the septal area, diagonal band nuclei, nucleus basalis (substantia innominata), and hypothalamus in the rhesus monkey. J Comp Neurol 214:170-197.

Morris RG, Gick ML, Craik FI (1988) Processing resources and age differences in working memory. Mem Cognit 16:362-366.

Murphy CT, McCarroll SA, Bargmann CI, Fraser A, Kamath RS, Ahringer J, Li H, Kenyon C (2003) Genes that act downstream of DAF-16 to influence the lifespan of Caenorhabditis elegans. Nature 424:277-283.

O’Donnell KA, Rapp PR, Hof PR (1999) Preservation of prefrontal cortical volume in behaviorally characterized aged macaque monkeys. Exp Neurol 160:300-310.

Ongur D, Price JL (2000) The organization of networks within the orbital and medial prefrontal cortex of rats, monkeys and humans. Cereb Cortex 10:206-219.

Owen AM, Herrod NJ, Menon DK, Clark JC, Downey SP, Carpenter TA, Minhas PS, Turkheimer FE, Williams EJ, Robbins TW, Sahakian BJ, Petrides M, Pickard JD (1999) Redefining the functional organization of working memory processes within human lateral prefrontal cortex. Eur J Neurosci 11:567-574.

Page TL, Einstein M, Duan H, He Y, Flores T, Rolshud D, Erwin JM, Wearne SL, Morrison JH, Hof PR (2002) Morphological alterations in neurons 
forming corticocortical projections in the neocortex of aged Patas monkeys. Neurosci Lett 317:37-41.

Pakkenberg B, Gunderson HJ (1997) Neocortical neuronal number in humans: effect of sex and age. J Comp Neurol 384:312-320.

Pandya DN, Yeterian EH (1990) Prefrontal cortex in relation to other cortical areas in rhesus monkey: architecture and connections. Prog Brain Res 85:63-94.

Pandya DN, Dye P, Butters N (1971) Efferent cortico-cortical projections of the prefrontal cortex in the rhesus monkey. Brain Res 31:35-46.

Peters A (2002) Structural changes in the normally aging cerebral cortex of primates. Prog Brain Res 136:455-465.

Peters A, Leahu D, Moss MB, McNally KJ (1994) The effects of aging on area 46 of the frontal cortex of the rhesus monkey. Cereb Cortex 4:621-635.

Peters A, Rosene DL, Moss MB, Kemper TL, Abraham CR, Tigges J, Albert MS (1996) Neurobiological bases of age-related cognitive decline in the rhesus monkey. J Neuropath Exp Neurol 55:861-874.

Quintana J, Fuster JM (1999) From perception to action: temporal integrative functions of prefrontal and parietal neurons. Cereb Cortex 9:213-221.

Rapp PR, Gallagher M (1997) Toward a cognitive neuroscience of normal aging. Adv Cell Aging Gerontol 2:1-21.

Rowe JB, Toni I, Josephs O, Frackowiak RS, Passingham RE (2000) The prefrontal cortex: response selection or maintenance within working memory? Science 288:1656-1660.

Salthouse TA (1992) Working-memory mediation of adult age differences in integrative reasoning. Mem Cognit 20:413-423.

Simic G, Kostovic I, Winblad B, Bogdanovic N (1997) Volume and number of neurons of the human hippocampal formation in normal aging and in Alzheimer's disease. J Comp Neurol 379:482-494.

Sloane JA, Hollander W, Rosene DL, Moss MB, Kemper T, Abraham CR (2000) Astrocytic hypertrophy and altered GFAP degradation with age in subcortical white matter of the rhesus monkey. Brain Res 862:1-10.

Smith DE, Roberts J, Gage FH, Tuszynski MH (1999) Age-associated neuronal atrophy occurs in the primate brain and is reversible by growth factor gene therapy. Proc Natl Acad Sci USA 96:10893-10898.
Smith TD, Adams MM, Gallagher M, Morrison JH, Rapp PR (2000) Circuitspecific alterations in hippocampal synaptophysin immunoreactivity predict spatial learning impairment in aged rats. J Neurosci 20:6587-6593.

Squire LR, Kandel ER (2000) Memory. New York: Scientific Am Library.

Tanila H, Shapiro M, Gallagher M, Eichenbaum H (1997) Brain aging: changes in the nature of information coding by the hippocampus. J Neurosci 17:5155-5166.

Tigges J, Herndon JG, Rosene DL (1995) Mild age-related changes in the dentate gyrus of adult rhesus monkeys. Acta Anat (Basel) 153:39-48.

Tuszynski MH, Armstrong DA, Gage FH (1990) Basal forebrain cell loss following fimbria/fornix transection. Brain Res 508:241-248.

Uemura E (1985a) Age-related changes in the subiculum of Macaca mulatta: synaptic density. Exp Neurol 87:403-411.

Uemura E (1985b) Age-related changes in the subiculum of Macaca mulatta: dendritic branching pattern. Exp Neurol 87:412-427.

Unger JW, Schmidt Y (1994) Neuropeptide Y and somatostatin in the neocortex of young and aging rats: response to nucleus basalis lesions. J Chem Neuroanat 7:25-34.

Ungerleider LG, Courtney SM, Haxby JV (1998) A neural system for human visual working memory. Proc Natl Acad Sci USA 95:883-890.

Vincent SL, Peters A, Tigges J (1989) Effects of aging on the neurons within area 17 of rhesus monkey cerebral cortex. Anat Rec 223:329-341.

Walker LC, Kitt CA, Struble RG, Wagster MV, Price DL, Cork LC (1988) The neural basis of memory decline in aged monkeys. Neurobiol Aging 9:657-666.

West MJ (1993) Regionally specific loss of neurons in the aging human hippocampus. NeurobiolAging 14:287-293.

West MJ, Ostergaard K, Andreassen OA, Finsen B (1996) Estimation of the number of somatostatin neurons in the striatum: an in situ hybridization study using the optical fractionator method. J Comp Neurol 370:11-22.

Zhang ZJ, Lappi DA, Wrenn CC, Milner TA, Wiley RG (1998) Selective lesion of the cholinergic basal forebrain causes a loss of cortical neuropeptide $\mathrm{Y}$ and somatostatin neurons. Brain Res 800:198-206. 